\title{
What evidence exists on the possible effects of urban forms on terrestrial biodiversity in western cities? A systematic map protocol
}

\author{
Morgane Flégeau ${ }^{*}$ (D) Hélène Soubelet ${ }^{1}$, Sophie Carré ${ }^{2}$, Sébastien Barot ${ }^{3}$, Xavier Lagurgue ${ }^{4}$,
} Sabine Bognon ${ }^{5}$ and Philippe Clergeau ${ }^{5}$

\begin{abstract}
Background: As urban areas expand, scientists now agree that the city is an important space for biodiversity conservation. Yet, still relatively little is known about how urban forms could have a differential impact on terrestrial species and ecosystems. If some reviews have been conducted to examine the link between biodiversity and urban characteristics at an infra-city scale, none have explored the relationship between urban organization and biodiversity and tried to assess the capacity of various urban forms to maintain and possibly favour flora and fauna in the city. The resulting map will present the state of knowledge regarding possible relationships between urban forms and its features on the establishment and settlement of terrestrial and temperate biodiversity at infra-city scale in western cities.

Methods: The systematic map will follow the Collaboration for Environmental Evidence (CEE) Guidelines. We will collect the relevant peer-reviewed and grey literature in French and English language. The scientific literature will be retrieved with the use of a search string in two publication databases, one environmental and one social science database (Web Of Science Core Collection, and Cairn.info). We will also perform supplementary searches (search engines, call for literature, search for relevant reviews). All references will be screened for relevance using a three-stage process, according to a predefined set of eligibility criteria. Our study will concentrate on urban areas at the infra-city scale in cities of the temperate biogeographical zone. The subject population will include terrestrial species and ecosystems, except for archaea and bacteria. The exposure will consider all types of urban forms described by any urban descriptors or measures including heterogeneity, fragmentation, housing density, organisation of urban matrix, urban fabric) and all types of urban features (e.g. size, age of the buildings, materials, urban artefacts). All relevant outcomes will be considered (e.g. species richness, abundance, behaviour). We will provide an open-access database of the studies included in the map. Our results will also be presented narratively, together with tables and graphs summarising the key information coded from the retained articles (e.g. study characteristics, types and areas of research that has been undertaken, types of exposure, population concerned, etc.).
\end{abstract}

Keywords: Urban biodiversity, Infra-city scale, Ecological connectivity, Density

*Correspondence: morgane.flegeau@fondationbiodiversite.fr ${ }^{1}$ French Foundation for Biodiversity Research (FRB), 195, rue Saint Jacques, 75005 Paris, France

Full list of author information is available at the end of the article

\section{Background}

Today, the majority of the world's population is concentrated in cities and the surfaces occupied by such urbanized land continue to expand [1]. Researchers now agree that urban spaces are important for biodiversity conservation $[2,3]$. Among other reasons, nature and biodiversity in cities are known to be essential for human health original author(s) and the source, provide a link to the Creative Commons licence, and indicate if changes were made. The images or other third party material in this article are included in the article's Creative Commons licence, unless indicated otherwise in a credit line to the material. If material is not included in the article's Creative Commons licence and your intended use is not permitted by statutory regulation or exceeds the permitted use, you will need to obtain permission directly from the copyright holder. To view a copy of this licence, visit http://creativecommons.org/licenses/by/4.0/. The Creative Commons Public Domain Dedication waiver (http://creativeco mmons.org/publicdomain/zero/1.0/) applies to the data made available in this article, unless otherwise stated in a credit line to the data. 
and well-being $[4,5]$. As a consequence, the greening of cities is promoted by urban policies, especially in their densely populated parts, to make them more liveable. However, researches show that access to green space is frequently associated with higher socio-economic classes, who tend to live in less dense neighbourhoods $[6$, 7]. As a result, greening and density policies may be seen by planners as difficult to reconcile [8]. As cities develop their biodiversity policies, more information concerning the impacts of different urban forms on terrestrial biodiversity is critical for urban planning and management to achieve specific desired biodiversity outcomes.

The characteristics of the urban environment provide specific conditions for establishment of biodiversity. By using the word "biodiversity", we include here all terrestrial species and terrestrial ecosystems except for archaea and bacteria. The extent of impervious surfaces is one of the specificities of urban context. Species richness declines and animal and plant species composition changes as urbanization intensifies [9, 10]. Research on urban biodiversity often considers cities through an urbanization gradient, from rural to urban-or vice versa, with the measurement of a proportion of impervious surface to assess the impact of urban environment on ecosystems. If it's practical to evaluate and intuitive [11] this type of indicator is often insufficient to explain ecological conditions in cities [12]. A city is also characterized by its spatial complexity and its great diversity from an architectural and historical point of view. At the infracity scale, various urban forms are superimposed on the urbanization gradient. Therefore, studies focusing on the urbanization gradient tend to simplify a much more complex reality.

Examining the forms of the built environment has been mostly the subject of various disciplines such as architecture, urban planning, or geography [13-16]. Depending on the classifications and criteria used to describe them, urban forms range from the densest inner-city spaces to the least crowded peri-urban transition zone. Urban forms follow several approaches, which correspond to various spatial scales and historical processes [17]. The multiplicity of the definitions and the variety of indicators used to define them can lead to confusion [18]. Here we chose to consider urban forms at the infra-city scale. Indeed, urban forms encompass physical characteristics in parts of the city and other nonphysical aspects, such as density. Due to resource limitations, we considered temperate western cities and their various urban forms (see Fig. 1 for examples). Studies on cities and urban areas often simplify the ecological processes in their body of work. Therefore, they provide few useful insights to understanding relationships between urban forms and terrestrial biodiversity.
In ecology, urban typologies can be described through composition and spatial configuration. It refers to landscape ecology theories [19]. Composition is the ratio of buildings in relation to green spaces and the second is the spatial arrangement of these items among themselves [20]. These configurations are the result of natural characteristics of the site and of historical, architectural, and cultural conditions in which the city was created and expanded. For each urban form, there are specific spatial organisations in terms of parcel grids, roads and builtup islands, urban fabrics, types of buildings, and public spaces [21]. It is then important to consider elements like width and length of the roads, size, age and orientation of the buildings, gauges, compactness, alignments or setbacks in relation to the street.

Many studies have focused on the different urban characteristics and their configuration in the urban context. Indeed, the configuration of green spaces in the city-including the organization of urban features, including green spaces (e.g. parks, urban woods, semi natural areas) and ecological corridors-can have a positive influence on habitats, on plants, and on animal species. They could also have a differentiated impact on flora and fauna at infra-city scale [11]. Other ecological studies have focused on certain types of urban forms, as suburban landscapes and showed that their spatial organisation can be important to biodiversity [22]. Moreover, some authors have addressed how different types of land use influence animal and plant species [23, 24]. In 2018, Jokimaki et al. highlighted that the densest urban areas can even harbour threatened bird species [25].

Yet, little seems to be known about the comparison of the capacity of different urban forms to preserve, maintain, or sustain biodiversity and ecosystems and ecosystem services. Some reviews have been carried out on the link between biodiversity and urban features at the infracity scale $[9,11,26,27]$. In 2000 , a review of the scientific literature showed that the differentiated impact of urban forms on fauna and flora was never formally tested in scientific works [28]. This topic is at the interface between urban ecology and urban studies, and also between the science and practice of urban planning and architecture. We may wonder about the impact of various types of urban morphologies, such as small collectives scattered over a large plot, residential areas with houses centred on their gardens, or even buildings arranged in closed blocks on biodiversity.

Furthermore, if greening the city may provide important ecosystem services to city dwellers, increasing biodiversity in cities therefore brings an element of sustainability to the system. Indeed, respecting the functioning of natural ecosystems (food chains, dispersion processes, mutualism...) may allow for the reduction in 


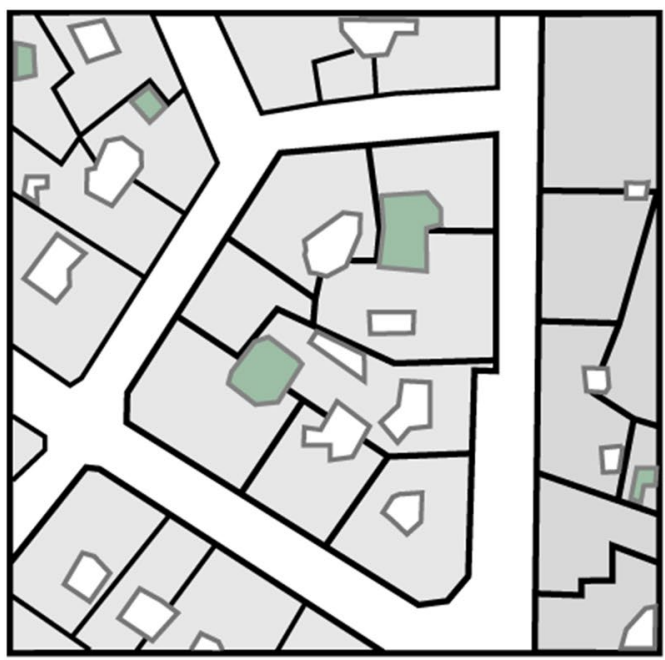

Dense urban form of city center

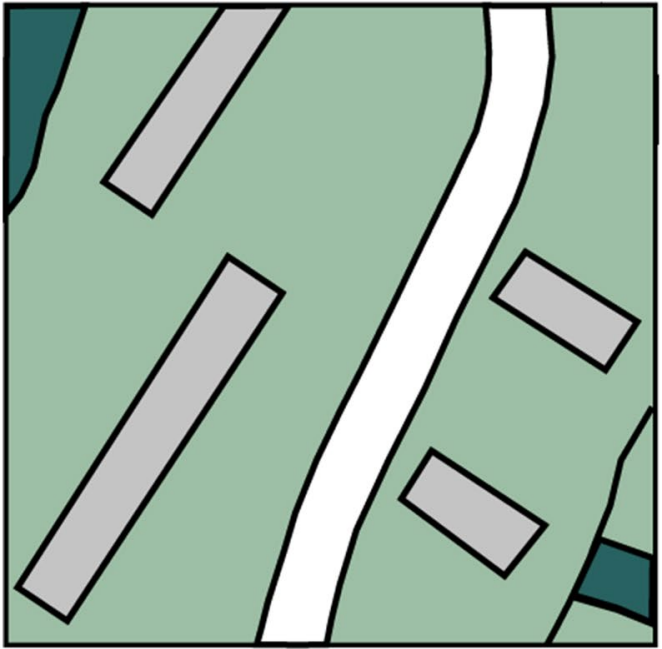

Large buildings installed on vegetalized surfaces

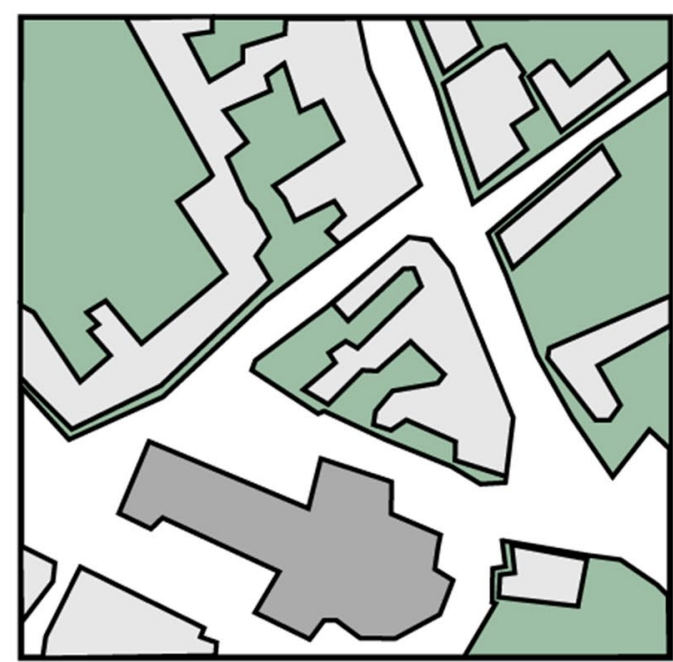

Spontaneous, low-density urban form

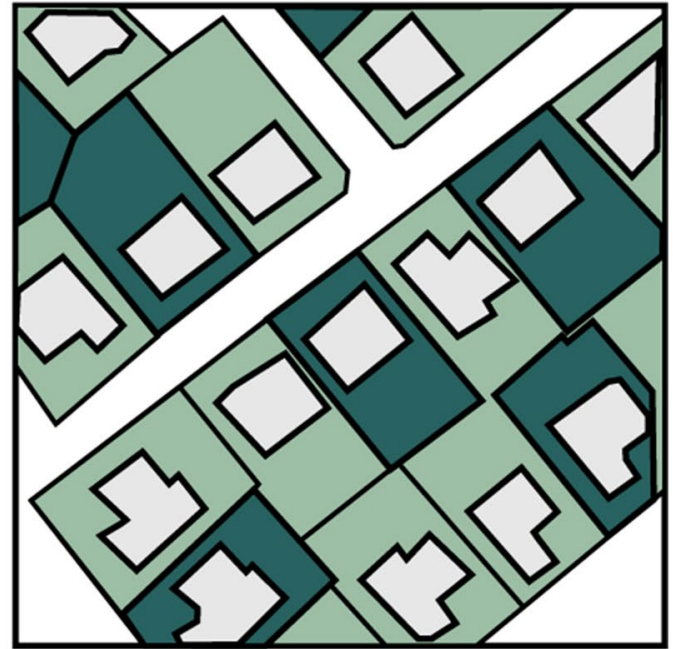

Single-family house with garden (housing estate, detached house)

Fig. 1 Illustration of various urban forms in western cities

management costs of green spaces, and for compensate any climatic or sanitation accident that could drive the disappearance of established species. Promoting biodiversity must therefore imply not only a diversity of species but also relationships between them and their environment. Taking into account ecological corridors or sufficient surfaces for species directly questions the way the urban organization is designed. By exploring the relationship between urban form and terrestrial biodiversity in the scientific literature, we thus aim to assess the capacity of urban forms to maintain animal and plant species in the city and also to provide answers to urban planners of temperate western cities to conduct urban projects including biodiversity.

\section{Stakeholder engagement}

This work is part of a broader program named BAUM (Biodiversity, Land use planning and Morphology), launched in 2019 by an interdepartmental agency of the French government, the PUCA (Plan Urbanism Construction Architecture). This program explores the possibility of reconciling the densification of buildings with the preservation of biodiversity in European cities. The results of this systematic map conducted on the links 
between terrestrial biodiversity and urban forms in temperate western cities will be able to enlighten the stakeholders on issues such as the impact of urban sprawl in France. BAUM program is supervised by a Scientific Council, composed of researchers, civil servants in charge of national public policies and various stakeholders from the private sector.

The Scientific Committee was consulted to suggest relevant literature (scientific and grey literature), specialist website and also eligibility criteria for article screening.

Within the Scientific Committee, a review team has been constituted. It is composed of the two project managers and three experts (SC, $\mathrm{PC}, \mathrm{SB}, \mathrm{HS}$ and $\mathrm{MF})$ :

- The PUCA called for the study and acts as Project lead. It is an interdepartmental agency of the French Ministry of Ecological and Solidarity Transition. Its aims are to improve knowledge on cities and territories. The PUCA initiates research and researchaction programs and experimentation in the field of land development, urban planning, housing, architecture, and construction to provide guidelines to public policies.

- The MNHN (French National Museum of Natural History) is a public organization dedicated to nature and its relationship with the human species. The Centre for Ecology and Conservation Sciences (CESCO) is a MNHN research laboratory, mainly composed of researchers specialized in conservation ecology and also human and social sciences. The CESCO is associated with the program by providing scientific support.

- The FRB (Foundation for Research on Biodiversity) created in 2008-brings together public research organisations, environmental protection associations, space and biological resource managers and companies. It is a point of convergence between science and society around the challenges facing biodiversity research today. The FRB has developed an expertise on systematic reviews and hosts the project's core team.

Finally, this review team is completed by two other researchers specializing in ecology (SB) and in architecture $(\mathrm{XL})$.

\section{Objective of the review}

The objective of this systematic map is to gather and synthesize studies that explore whether different types of urban development (exposure) can have a differential impact (outcomes) on terrestrial species and ecosystems (population).

\section{Primary question}

What is the range and extent of evidence on the effects of urban forms and features on the establishment of terrestrial and temperate biodiversity at the infra-city scale, in urban areas of Europe, North America, New Zealand, and Australia?

- Secondary questions:

- What are the categories of urban forms most studied? What are the variables most used to describe urban features?

- What are the most commonly described outcomes?

- In which countries have the most studies been conducted?

- What research fields study this interface topic?

- What are the most used study designs?

\section{Methods}

This review strictly follows the CEE guidelines [29] and conforms to the ROSES reporting standards (30) [see Additional file 1].

\section{Searching for articles Languages}

Due to limited resources and also to the languages understood by the review team, only studies published in English and in French will be included in this systematic map. A large body of scientific literature is available in English and research reports and grey literature are accessible in French.

\section{Search string}

The search string based on PECO (Population, Exposure, Comparator, Outcomes) keywords in English was built based on a scoping exercise conducted in "Web of Science Core Collection" database in June 2019. A detailed description of the PECO elements that we used for the systematic map is presented in Table 1.

Search terms were initially identified from articles of a test-list and then discussed and validated by the review team. They were organized into four blocks [see Additional file 2 search string complete with excluded words].

- Block A: descriptors of ur context

- Block B: descriptors population

- Block C: descriptors outcomes

- Block D: descriptors exposure

In each block, search terms were combined using the Boolean operator "OR" and the four blocks were combined using the Boolean operator "AND" i.e., 'A' AND 'B' AND ' $C$ ' AND ' $D$ '. This search string was structured in 
Table 1 PECO elements

\begin{tabular}{|c|c|}
\hline PECO & Description \\
\hline Population & $\begin{array}{l}\text { All terrestrial species and terrestrial ecosystems except for archaea and bacteria in cities of the temperate biogeographical zone (accord- } \\
\text { ing to Olson \& Dinerstein (1998) classification of biomes: temperate broadleaf and mixed forests, temperate coniferous forests and } \\
\text { Mediterranean forests, woodlands and scrub). Due to resource limitations, we only considered temperate western cities }\end{array}$ \\
\hline Exposure & $\begin{array}{l}\text { All types of urban forms described by any urban descriptor or measure including heterogeneity, fragmentation, housing density, organi- } \\
\text { sation of the urban matrix, urban fabric) and all types of urban features (e.g. size, age of the buildings, materials, urban artefacts). A first } \\
\text { list of urban forms and features expected to be found in the literature has been discussed within the scientific committee of BAUM. To } \\
\text { provide a frame to this work, the keywords have been categorized into four groups. They are related to urban forms, urban morphology } \\
\text { and density, process of urbanization, functions and finally to street furniture. They are described below: } \\
\text { - Urban form: allotment, architecture, boulevard, centre, collective, dwelling, district, historical centre, intra-urban, metropolis, neigh- } \\
\text { bourhood, peri-urban, public green space, road, suburb, urban fabric, wasteland } \\
\text { - Urban morphology: arrangement, block, complexity, connectivity, continuous, disturbance, heterogeneity, dimension, discontinuous, } \\
\text { division, fragmentation, heterogeneity, mosaic, shape, structure } \\
\text { Density: compactness, gradient, urbanization level, land cover, land use, housing density } \\
\text { - Urbanization process: urban sprawl, urban renewal, pattern, polycentric development, renaturation } \\
\text { - Urban functions: commercial, residential, industrial } \\
\text { Street furniture: bench, lamppost and pavement } \\
\text { All types of urban forms will be considered and described }\end{array}$ \\
\hline Comparator & Alternative urban forms or previous urban forms \\
\hline Outcomes & $\begin{array}{l}\text { Any descriptors of presence or absence of the population including, but not restricted to, abundance of species, diversity of species, } \\
\text { and behaviour of species. Outcomes studied will include: ecosystem services, functional characteristics, functional composition, func- } \\
\text { tional feature, species richness, abundance, amount, assemblage, colonization, dispersion, diversity ecological process, function, habitat, } \\
\text { index, management of soil, migration number, population, presence, proportion, population structure, viability }\end{array}$ \\
\hline Context & All urban areas at the infra-city scale (scale of observation of the urban form) \\
\hline
\end{tabular}

four elements related to Context, Population, Outcomes and Exposure:

A (Context) AND B (Population) AND C (Outcomes) AND D (Exposure).

It was adopted to limit the number of results, because of time and human resources limitations, after some preliminary searches. The search string was built by successive iterations, starting with the whole list of key words and refined to maximise the comprehensiveness of the equation with the test list. The search string that produced the highest efficiency is presented below.

$\mathrm{TS}=$

((cities OR city OR commercial OR district* OR industr* OR intra-urban OR metropol* OR neighborhood OR peri-urban OR residential OR suburb* OR town* OR urban* OR "urban planning" OR street* OR road* OR boulevard*).

AND

(arthropod*

OR biodiversity OR "ecological communit*" OR "biological communit*" OR ecosystem* OR bird OR mammal OR reptile OR amphibian OR insect OR species OR vegetation OR soil).

AND

("eco\$system service*" OR "functional characteris*" OR "functional compo*" OR "functional featur*" OR "species richness" OR abund* OR amount OR assembl* OR colonis* OR dispers* OR divers* OR "ecological process" $*$ OR function* OR habitat OR index OR "management of soil*" OR migrati* OR number* OR population* OR presence* OR proportion* OR "population structur*" OR viab*).

\section{AND}

("collective dwelling*" OR compact* OR "disturbance heterogeneity" OR allotment OR arrangement* OR block* OR complex* OR connecti* OR continu* OR densit* OR design* OR dimension OR discontinuous OR division OR edge-effect OR form* OR fragment* OR "functional corridor".

OR geometr* OR gradient* OR habitat OR "habitat diversity" OR "habitat patch" ${ }^{*}$ OR heterogene* OR "housing density" OR "intermediate disturbance" OR island* OR landscape* OR land-cover* OR land-use* OR LULC OR matrix OR microhabitat OR mosaic OR NDVI OR parcel* OR "patch area" OR "patch size" OR patch* OR pattern* OR plot* OR "polycentric development" OR "public green space" OR "renaturation" OR sector* OR shape OR simplif* OR "spatial diversity" OR "spatial heterogeneity" OR "spatial pattern*" OR "stepping-stone" OR structure OR "transit-oriented development" OR "urbanization level" OR "urban fabric" OR "urban sprawl" OR "urban renewal" OR wasteland OR composition OR configuration OR organization)).

\section{Comprehensiveness of the search}

To check the performance of the search strategy, a test list of 30 scientific articles (presented in Additional file 3) was initially obtained from experts of the review team, 
from various existing reviews, by searching on Google, and in grey literature sources.

On the basis of the criteria listed above, we chose to do the bibliographic search on two databases:

- "Web of Science Core Collection" on the Web of Science platform (Clarivate) to which the review team had access via the team's members institution (INRA subscription of HS). As explained above, a scoping exercise was conducted using this database. Our search string was run on 6th of June 2019 and covered SCI-EXPANDED, SSCI, A\&HCI, CPCI-S, CPCI-SSH, BKCI-S, BKCI-SSH, ESCI and CCREXPANDED, without any timespan restriction.

- "Cairn.info" to which the review team had access via the team's members institution. This social sciences database includes studies published in French and in English. Another scoping exercise has been conducted. The search string was made using the following terms: (urban form OR urban morphology OR infra-city OR city OR town) AND (biodiversity OR animals OR plants). Our search string was run on 7th of June 2019 without any timespan restriction.

A total of 29,523 articles were listed in both databases. 26,672 of them were referenced in WOS CC and 2851 of the articles of the test list were indexed in Cairn. Consequently, combining the two databases, the search comprehensiveness was 100\% [see Additional file 3].

\section{Bibliographic databases}

We first listed the peer-reviewed databases to which the members of our review team had access, databases that covered ecology and also humanities and that guaranteed reproducibility. The following publication databases have been listed and will be included in the search strategy:

- WOSCC

- Cairn.info (https://www.cairn.info/)

- Persée (https://www.persee.fr/)

- Archinform(https://www.archinform.net/)

- Urbamet (http://www.urbamet.com/)

- ArchiRès (https://www.archires.archi.fr/)

Due to the project's resource limitations (in terms of time, and financial resources), we were not able to search more than two web-based search engines. Because of the position of the subject at the science-society interface, we chose to explore at least one environmental database and one social science database. This choice is consistent with the number of articles obtained during the scoping exercise.

\section{Web-based search engines}

Additional searches will be performed using Google Scholar search engine. The search will be limited to the first 200 results according to the limited effectiveness of this web-based academic search engine for evidence reviews [31]. The relevant peer-reviewed articles in English will be collect, without any timespan restriction, using the search terms combined:

Urban form AND biodiversity.

\section{Supplementary searches}

To maximize the coverage of results, different sources of literature will be investigated since the topic of this systematic map straddles the science and practice of urban planning. The aim of collecting grey literature is therefore to provide the broadest possible overview of professional and operational productions in the urban planning field. The search will be carried with the help of an intern during one month in order to collect writings of the stakeholders of public institutions, design offices, associations.

The search for grey, professional, and operational literature will be carried out through Internet searches. A broader search will be made using the following French terms:

(«Forme urbaine» OR « Morphologie urbaine») AND biodiversité.

Indeed, this broader search for grey literature will be conducted in French (language spoken by the review team) since the research program including the systematic map is a French ministry agency. We identified a preliminary set list of sources [see Additional file 4].

\section{Specialist websites}

We will search for additional literature in French with the following search terms: (Forme urbaine OR Morphologie urbaine) AND biodiversité.

The following websites of French specialist organizations will be searched for relevant publications:

- Document portal of the French Ecology Ministry (http://portail.documentation. developpementdurable.gouv.fr/)

- Documental portal of French biodiversity office (OFB) (https://ofb.gouv.fr/documentation)

- Resource Centre of green and blue infrastructure (http://www.trameverteetbleue.fr/documentationoutils/)

- Database of the Centre for studies and expertise on risks, the environment, mobility and development (https://www.cerema.fr/fr/centre-ressources/) 
- Document database of the Centre for landscape and urban horticulture (Plante \& Cité) (https:// www.plante-et-cite.fr/recherche/ressource_view/

- Document database of the Paris Urbanism Agency (Apur) (https://www.apur.org/en/our-works)

- The Economic, Social and Environmental Council (https://www.lecese.fr/travaux-du-cese/travauxpublies)

- Documentation centre of the PUCA (http://www. urbanisme-puca.gouv.fr/centres-de-documentationr49.html)

- Regional biodiversity agency of Paris region (https:// www.arb-idf.fr/ressources

- Departmental observatory of urban biodiversity of the Seine-Saint-Denis (https://ressources.seinesaint denis.fr/-Observatoire-Departemental-de-la-Biodi versite-Urbaine-193-)

- Documentation centre of the Ecological transition Agency (ADEME)(https://www.ademe.fr/en/media theque)

- Documentary resources of the French capitals of biodiversity (http://www.capitale-biodiversite.fr/resso urces-documentaires)

- French League for the Protection of Birds (https:// www.lpo.fr/loisirs-nature)

- French ÉcoQuartier label documentation centre (http://www.ecoquartiers.logement.gouv.fr/docum ents/)

The resources will be collected by browsing the document collections of public institutions, academic institutions and associations, and consulted on the Google search engine.

A call for grey literature will be conducted through the Scientific Council of our project to find non-peerreviewed literature, including reports published in French, articles from professional journals of urban planning and architecture. All members of the Scientific Council have been asked to provide documents that they considered relevant to the subject.

\section{Duplicate removal}

All articles will be exported into different collections using the reference management software Zotero ${ }^{\circledR}$ and merged into one database after the export. All duplicates will be removed manually in Excel. We will not use review management software to screen and code literature.

\section{Article screening and study eligibility criteria Screening process}

All the articles obtained by the search process will be screened according to a three-stage selection procedure. The screening of titles, abstracts, and full-texts will be performed by two reviewers independently (MF and HS). The four other members of the review team will help during the abstract screening stage (SC, SB, XL, SB and PC). If there is disagreement between the two primary reviewers (MF and HS), the inclusion or exclusion of the article will be discussed with all members of the review team.

A Kappa test will be performed by all the reviewers (HS, MF, SC, SB, XL, SB, and PC) at each screening stage. A random sample of $10 \%$ of the titles (after duplicate removal), $10 \%$ of the retained abstracts, and $10 \%$ of the retained full-texts will be selected and each of the seven reviewers will screen this sample independently. The operation will be repeated until reaching a Kappa score $\geq 0.6$. Any disagreements will be identified and discussed between the reviewers. The criteria for rejection of an article will be decided, discussed, and validated by the review team.

During the scoping stage conducted in the "Web of Science Core Collection", the three stages of the screening process were tested by one reviewer (MF) in order to refine the eligibility criteria. A second reviewer will examine the rejected articles during each sorting stage to assess the consistency of the inclusion/exclusion decisions. Thus, an a posteriori cross check will determine if articles are re-included or not.

The details of the final decision of inclusion or exclusion of articles selected at the full-text screening stage (with the reason of exclusion) will be provided in an Excel database [see Additional file 5].

\section{Eligibility criteria}

Eligibility criteria were developed in consultation with the review team at each stage of the screening process. In any case of doubt regarding the presence of a relevant inclusion criterion or if there is insufficient information to make an informed decision, articles will be retained for assessment at a later stage. The articles accepted based on their titles but without any abstracts will pass by default to the full-text screening stage.

To be included in our systematic map, studies must attain the criteria of exposure detailed in Table 2. We used increasingly precise criteria from the first screening step to the last in order to retain articles that could have otherwise been excluded because of a lack of precision/ detail in the title or in an abstract, concerning the study scale.

\section{Title}

\section{Inclusion criteria}

Firstly, all titles will be retained if presence both of any terms related to cities or urban environment and terrestrial species (wild animal and plants) or ecosystems. 
Table 2 Inclusion and exclusion criteria for the title screening

\begin{tabular}{|c|c|c|}
\hline & Inclusion criteria & Exclusion criteria \\
\hline Population & All terrestrial species (wild animal and plants) and ecosystems & $\begin{array}{l}\text { Freshwater, marine, and coastal biodiversity and ecosystems } \\
\text { Micro-organisms (archaea and bacteria) }\end{array}$ \\
\hline Exposure & $\begin{array}{l}\text { All types of urban features (e.g. materials used, size or age of } \\
\text { buildings) or urban form (e.g. historical centre, residential area). } \\
\text { A first list of exposure is identified here: } \\
\text { - Urban form: allotment, architecture, boulevard, centre, collec- } \\
\text { tive, dwelling, district, historical centre, intra-urban, metropolis, } \\
\text { neighbourhood, peri-urban, public green space, road, suburb, } \\
\text { urban fabric, wasteland } \\
\text { - Urban morphology: arrangement, block, complexity, con- } \\
\text { nectivity, continuous, disturbance, heterogeneity, dimension, } \\
\text { discontinuous, division, fragmentation, heterogeneity, mosaic, } \\
\text { shape, structure } \\
\text { Density: compactness, density, gradient, urbanization level, } \\
\text { land cover, land use, housing density } \\
\text { - Urbanization process: urban sprawl, urban renewal, pattern, } \\
\text { polycentric development, renaturation } \\
\text { - Urban functions: commercial, residential, industrial } \\
\text { Street furniture: bench, lamppost and pavement }\end{array}$ & $\begin{array}{l}\text { Other types of exposure in the urban environment (e.g. physico- } \\
\text { chemical and climatic exposure) }\end{array}$ \\
\hline Outcomes & $\begin{array}{l}\text { All outcomes related to the included populations including, but } \\
\text { not restricted to, biology/physiology (e.g. body size, growth), } \\
\text { space use (e.g. species distribution, individual movements), } \\
\text { ecosystem composition (e.g. species richness, abundance) and } \\
\text { species behaviour (e.g. reproduction, predation) }\end{array}$ & $\begin{array}{l}\text { Measures of genetic, physico-chemical or chemical variables (e.g.: } \\
\text { climate, temperature, carbone storage) }\end{array}$ \\
\hline Context & $\begin{array}{l}\text { Intra-urban or city scale in cities of the temperate biogeograph- } \\
\text { ical zone according to Olson \& Dinerstein (1998) classification } \\
\text { of biomes: temperate broadleaf and mixed forests, temperate } \\
\text { coniferous forests and Mediterranean forests, woodlands and } \\
\text { scrub }\end{array}$ & $\begin{array}{l}\text {-Reference to rural context; } \\
\text {-National or regional scale; } \\
\text {-All other biogeographical zones (e.g.: tropical, boreal) }\end{array}$ \\
\hline Language & Any article written in English or in French & \\
\hline Type of document & $\begin{array}{l}\text { Peer-reviewed journal article, book chapter, reports, PhD thesis, } \\
\text { conference abstract and presentation, grey literature }\end{array}$ & $\begin{array}{l}\text { Non-peer-reviewed articles, editorial material, letters or news } \\
\text { item, posters }\end{array}$ \\
\hline Type of content & In situ studies and modelling studies & Reviews and meta-analyses \\
\hline
\end{tabular}

\section{Exclusion criteria}

If there is absence of explicit mention of urban or biodiversity related terms in title, the articles will be excluded.

\section{Abstract Inclusion criteria}

Articles will be retained if terms related to infra-city district scale, urban features are present, and if the study design includes a spatial comparison (alternative urban forms) or a temporal comparison (previous urban forms).

\section{Exclusion criteria}

Articles will be excluded if urban context or urban forms are treated in a vague manner or even unspecified. An abstract will also be rejected if the urban category studied relates to articles treating urban functions (e.g.: commercial, industrial or residential for example). This also includes management of biodiversity and functions of infrastructure and architectural elements. For instance, if an article deals with the impact of lamp posts on bird communities, the screening will be done on whether it is part of an urban composition (and will be considered as part of the "form" category) or whether it is considered through production of light and therefore as a disturbance for animal species.

\section{Full text}

\section{Inclusion criteria}

During screening of full-texts, a distinction will be made based on a higher degree of accuracy of the description of the urban exposure. We will focus on articles addressing elements of urban infrastructure (e.g. material, architecture) or elements (e.g. streets, avenues) and, in particular different types of urban forms (e.g. collective district or low-density area). The final screen will be based on urban descriptors and features, preferably quantitative. Articles that accurately describe the urban descriptors in their results will be selected and will be the most relevant articles for our subject. These articles will include at least two quantified urban descriptors.

To truly focus on urban forms at the infra-city scale, we will apply a final exclusion criterion, discussed and validated by the review team. We will exclude the articles addressing the interface between spaces supporting 
biodiversity linked to their urban environment (connectivity, fragmentation, permeability of the matrix, etc.) and the urban matrix. This category includes articles dealing with various types of green spaces and their interface with urban context.

\section{Study validity assessment}

No study validity assessment will be performed because the intention of the map is not to examine the robustness of the study designs. However, our data coding strategy will include information regarding the design of each study, The data produced could be used further by users of this systematic map to assess the evidence presented in the article.

\section{Data coding strategy}

Key data from the selected articles after the three screening stages will be extracted based on the PECO structure using an a priori specified Codebook, a predefined spreadsheet that was discussed and validated by the review team [the articles used to assess the effectiveness of the data coding strategy are listed in Additional file 6]. Each article will be coded based on the full text using keywords and expanded comments fields describing various aspects of the study [See the codebook in Additional file 5]. In case studies lack detail on the information required or if details need to be clarified during the review process, the corresponding authors will be contacted by email.

\section{Study description}

- Basic bibliographic information (authors, title, journal, publication date, etc.)

- Study site, country of the study and region
- Study content (study, meeting abstract, news, editorial, commentary, correspondence, communication...)

- Publication type (journal article, book, conference proceedings, report, MSc thesis, PhD thesis, technical documentation, other)

\section{Study characteristics}

- Population: type of taxa studied (species or species group);

- Type of exposure (detailed in Table 3): set of elements that describe the urban form (e.g. historical centre, residential area) and its descriptive variables (e.g.: buildings age or height, land use);

- Outcome characteristics: category of outcomes (e.g.: abundance or specific richness loss or gain, behaviour), external factors (e.g.: season and timing of measurement);

- Comparators: spatial comparison (alternative urban forms) or temporal comparator (previous urban form)

Each article selected at full-text stage will be double coded by two members of the review team to ensure the consistency and accuracy of data extraction. If this type of coding is not possible due to limited resources, four members of the review team will independently carry out an a posteriori crosscheck on the meta-data of 10 publications randomly chosen at the first stage of the screening process. To test agreement between reviewers, Kappa scores will be calculated. Any disagreement will be discussed and the eligibility criteria will be revised to improve the data coding strategy. This process will be carried out until reaching Kappa score $\geq 0.6$.

Table 3 Categories of exposure to code in the systematic map

\begin{tabular}{|c|c|c|}
\hline Categories of exposure & Description & $\begin{array}{l}\text { Example reference } \\
\text { from test list or scoping } \\
\text { exercise }\end{array}$ \\
\hline Morphological characteristics & Description of street widths and its spatial organization, building heights & [32] \\
\hline Connectivity & $\begin{array}{l}\text { Connectivity between urban items and vegetated areas (green spaces, urban gardens, } \\
\text { remnants, etc.) }\end{array}$ & [33] \\
\hline Urban development scenarios & Use of urban or ecological modelization & {$[34]$} \\
\hline Urban projects & Comparing spaces before and after the construction of urban projects & {$[35]$} \\
\hline Urban density & Study of sectors characterized by a variable density of housing, buildings and population & {$[37]$} \\
\hline Major types of urban areas & $\begin{array}{l}\text { Either large sectors such as "dense urban", "suburban", etc., in terms of degree of compact- } \\
\text { ness or land-use patterns or description of the urban form through function (e.g. residen- } \\
\text { tial, business areas, industrial) }\end{array}$ & {$[38]$} \\
\hline Urbanization gradient & $\begin{array}{l}\text { Description of types of urban form even if the discriminating element is the percentage of } \\
\text { urban land use by impervious surfaces }\end{array}$ & [39] \\
\hline
\end{tabular}




\section{Study mapping and presentation}

We will produce an open-access database (Microsoft Excel sheet) including all the studies that meet our inclusion criteria and coded metadata. It will be included as an appendix to the systematic map. Where there is more than one study included in an article, each study will be recorded as a specific entry in the database i.e. one line per study. There will be several lines for each article if necessary.

The systematic map report will include summary figures and tables. Possible knowledge gaps (un- or underrepresented subtopics that warrant further primary research) and knowledge clusters (well-represented subtopics for full synthesis by a systematic review) will be identified e.g. by cross-tabulating key meta-data variables in heat maps (e.g. biological groups and outcomes). We will use our categorization of urban descriptors and outcomes to identify where there is a lack of knowledge and for which species. Interactive maps will be produced to present the data according to urban forms and make them more accessible and easily viewed. We will also pay attention to study designs and to the comparators used in the body of literature collected. Based on these results, recommendations will be made on priorities for future research on the effect of urban form on biodiversity.

\section{Supplementary Information}

The online version contains supplementary material available at https://doi. org/10.1186/s13750-021-00243-x.

Additional file 1. ROSES systematic map protocols checklist.

Additional file 2. Search string complete. Details of the scoping exercise performed to build the search string

Additional file 3. Test-list. List of 30 articles selected to assess the effectiveness of the search string.

Additional file 4. Set list of the grey literature sources identified.

Additional file 5. Codebook of the study. Presentation of the criteria used to data that will be extracted in the systematic map.

Additional file 6. List of 29 articles selected to assess the effectiveness of the data coding strategy.

\section{Acknowledgements}

The authors thank Romain Sordello and Joseph Langridge for providing useful comments on the protocol, Barbara Livoreil for her advice at the onset of this work, regarding the methodology of systematic reviews and Camille Huberts for her help with the search for grey literature. We also want to thank the anonymous reviewers as well as the editor for their precious comments and suggestions during the peer-review process.

\section{Authors' contributions}

This systematic review protocol is based on a draft written by MF and all authors contributed to the final version. All authors read and approved the final manuscritp.

\section{Funding}

This map was funded by the French Ministry of Ecological and Solidarity Transition and the French Fundation for Research on Biodiversity.
Availability of data and materials

All data generated or analysed during this study are included in this article and its Additional files.

\section{Declarations}

Ethics approval and consent to participate

Not applicable.

\section{Consent for publication}

Not applicable.

\section{Competing interests}

The authors declare that they have no competing interests.

\section{Author details}

${ }^{1}$ French Foundation for Biodiversity Research (FRB), 195, rue Saint Jacques, 75005 Paris, France. ${ }^{2}$ Plan Urbanism Construction Architecture (PUCA), French Ministry of Ecological and Solidarity Transition, Grande Arche de la Défense - Arche Sud, 92055 La Défense, France. ${ }^{3}$ French National Research Institue for Sustainable Development, 54 Boulevard Raspail, 75006 Paris, France. ${ }^{4}$ National School of Architecture Paris Val de Seine, 3/15 quai Panhard et Levassor, 75013 Paris, France. ${ }^{5}$ French National Museum of Natural History (MNHN), 43/61 rue Buffon, 75005 Paris, France.

Received: 15 October 2020 Accepted: 1 October 2021

Published online: 19 October 2021

\section{References}

1. United Nations. World population prospects 2019: Highlights. United Nations, Department of Economic and Social Affairs, Population Division; Report, 2019. p. 46.

2. Aronson MFJ, Lepczyk CA, Evans KL, Goddard MA, Lerman SB, Maclvor $J S$, et al. Biodiversity in the city: key challenges for urban green space management. Front Ecol Environ . 2017;15(4):189-96.

3. Lepczyk CA, Aronson MFJ, Evans KL, Goddard MA, Lerman SB, Maclvor JS. Biodiversity in the city: fundamental questions for understanding the ecology of urban green spaces for biodiversity conservation. Bioscience. 2017;67(9):799-807.

4. Fuller RA, Irvine KN, Devine-Wright P, Warren PH, Gaston KJ. Psychological benefits of greenspace increase with biodiversity. Biol Lett. 2007:3(4):390-4.

5. Keniger L, Gaston K, Irvine K, Fuller R. What are the benefits of interacting with nature? IJERPH. 2013;10(3):913-35.

6. Boone CG, Buckley GL, Grove JM, Sister C. Parks and people: an environmental justice inquiry in Baltimore, Maryland. Ann Assoc Am Geogr. 2009;99(4):767-87.

7. Ferguson M, Roberts HE, McEachan RRC, Dallimer M. Contrasting distributions of urban green infrastructure across social and ethno-racial groups. Landsc Urban Plan. 2018;175:136-48.

8. Haaland C, van den Bosch CK. Challenges and strategies for urban greenspace planning in cities undergoing densification: a review. Urban For Urban Green. 2015;14(4):760-71.

9. McKinney ML. Effects of urbanization on species richness: a review of plants and animals. Urban Ecosyst. 2008;11(2):161-76.

10. Concepcion ED, Moretti M, Altermatt F, Nobis MP, Obrist MK. Impacts of urbanisation on biodiversity: the role of species mobility, degree of specialisation and spatial scale. Oikos. 2015;124(12):1571-82.

11. Beninde J, Veith M, Hochkirch A. Biodiversity in cities needs space: a meta-analysis of factors determining intra-urban biodiversity variation. Ecol Lett. 2015;18(6):581-92.

12. Alberti M. The effects of urban patterns on ecosystem function. Int Reg Sci Rev. 2005;28(2):168-92.

13. Kropf K. "Morphological Investigations: Cutting into the Substance of Urban Form." In : Built Environment. 2011;37(4):393-408. http://www.jstor. org/stable/23290029.

14. Marshall S. Streets and patterns. London: Spon Press; 2005. p. 312. 
15. Moudon A. Urban morphology as an emerging interdisciplinary field. In: Urban morphology. 1997;1(1):3-10.

16. Panerai P, Demorgon M, Depaule J-C. Analyse urbaine. Marseille: Parenthèses; 1999. p. 189.

17. Raimbault J, Perret J. Generating urban morphologies at large scales. Newcastle: United Kingdom; 2019. p. 179-86.

18. Ahmadian E, Sodagar B, Mills G, Byrd H, Bingham C, Zolotas A. Sustainable cities: the relationships between urban built forms and density indicators. Cities. 2019;95:102382

19. Wu J. Landscape ecology. In: Leemans R, editor. Ecological systems. New York: Springer; 2013. p. 179-200.

20. Pellissier V, Cohen M, Boulay A, Clergeau P. Birds are also sensitive to landscape composition and configuration within the city centre. Landsc Urban Plan. 2012;104(2):181-8.

21. Panerai P, Castex J, Depaule J-C. Formes urbaines: de lîlot à la barre. Marseille: Editions Parenthèses; 1997. p. 196.

22. Marzluff JM, Rodewald AD. Conserving biodiversity in urbanizing areas: nontraditional views from a bird's perspective. CATE. 2008;1(2):1-27.

23. Fernandez-Juricic E. Avifaunal use of wooded streets in an urban landscape. Conserv Biol. 2000;14(2):513-21.

24. Smith R, Gaston K, Warren P, Thompson K. Urban domestic gardens (V): relationships between landcover composition, housing and landscape. Landscape Ecol. 2005;20(2):235-53.

25. Jokimaki J, Suhonen J, Kaisanlahti-Jokimaki M-L. Urban core areas are important for species conservation: a European-level analysis of breeding bird species. Landsc Urban Plan. 2018;178:73-81.

26. Nielsen $A B$, van den Bosch M, Maruthaveeran $S$, van den Bosch CK. Species richness in urban parks and its drivers: a review of empirical evidence. Urban Ecosyst . 2014;17(1):305-27.

27. Urbanova T. How to support avian diversity in an urban landscape: a bibliography. J Plan Lit. 2009;24(2):123-36.

28. Alberti M. Urban form and ecosystem dynamics : empirical evidence and practical implications. In: Achieving us stainable urban form. London: Taylor \& Francis; 2000. p. 84-96.

29. Collaboration for Environmental Evidence. In: Pullin A, Frampton G, Livoreil B, Petrokofsky G, editors. Guidelines and standards for evidence synthesis in environmental management, Version 50. 2018.
30. Haddaway N, Macura B, Whaley P, Pullin A. ROSES flow diagram for systematic reviews. Version 1.0. 2018. https://figshare.com/articles/ROSES_ Flow_Diagram_Version_1_0/5897389/3. Accessed 31 Jul 2020.

31. Haddaway NR, Collins AM, Coughlin D, Kirk S. The role of google scholar in evidence reviews and its applicability to grey literature searching. Wray KB, editor. PLOS ONE. 2015;10(9):e0138237.

32. Murgui E. Factors influencing the bird community of urban wooded streets along an annual cycle. Ornis Fennica. 2007;84(2):66-77.

33. Bierwagen B. Predicting ecological connectivity in urbanizing landscapes. Environ Plann B Plann Des. 2005;32(5):763-76.

34. Tannier C, Foltete J-C, Girardet X. Assessing the capacity of different urban forms to preserve the connectivity of ecological habitats. Landsc Urban Plan . 2012;105(1-2):128-39.

35. Hostetler M, Duncan S, Paul J. Post-construction effects of an urban development on migrating, resident, and wintering birds. Southeast Nat. 2005:4(3):421-34

36. Varet M, Burel F, Petillon J. Can urban consolidation limit local biodiversity erosion? Responses from carabid beetle and spider assemblages in Western France. Urban Ecosyst . 2014;17(1):123-37.

37. Soga M, Yamaura Y, Koike S, Gaston KJ. Land sharing vs land sparing: does the compact city reconcile urban development and biodiversity conservation? Rhodes J, editor. J Appl Ecol. 2014;51(5):1378-86.

38. Andersson E, Colding J. Understanding how built urban form influences biodiversity. Urban For Urban Green . 2014;13(2):221-6.

39. Avondet J, Blair R, Berg D, Ebbert M. Drosophila (Diptera : Drosophilidae) response to changes in ecological parameters across an urban gradient. Environ Entomol. 2003:32(2):347-58.

\section{Publisher's Note}

Springer Nature remains neutral with regard to jurisdictional claims in published maps and institutional affiliations.
Ready to submit your research? Choose BMC and benefit from:

- fast, convenient online submission

- thorough peer review by experienced researchers in your field

- rapid publication on acceptance

- support for research data, including large and complex data types

- gold Open Access which fosters wider collaboration and increased citations

- maximum visibility for your research: over $100 \mathrm{M}$ website views per year

At $\mathrm{BMC}$, research is always in progress.

Learn more biomedcentral.com/submissions 